\title{
Marketing viral y abstención electoral juvenil
}

\author{
Rojas M., Lenin A.* \\ Saavedra T., José Luis ${ }^{* *}$
}

\section{Resumen}

La investigación tuvo como objetivo analizar las causas de la abstención electoral en jóvenes votantes y determinar el impacto del marketing viral como motivador del voto. Teóricamente se abordó el marketing viral (Sanagustin, 2010; Calderón, 2011) y la abstención electoral (Ugarte et al, 2013; Trilla et al, 2010). La investigación, de tipo descriptivo, asumió una población de 926.484 ciudadanos inscritos en el Consejo Nacional Electoral y una muestra de 156 unidades con edades entre 18 y 30 años, habilitados para votar en las elecciones municipales para alcalde de Maracaibo (Venezuela) en el año 2013. En resultados obtenidos destaca que las causas psicológicas y políticas originan la abstención juvenil, el Consejo Nacional Electoral no cumple con las fases del marketing viral, y el seguimiento en redes sociales por parte de los electores y el conocimiento de la acciones de comunicación del ente comicial influyen en incentivar al electorado a participar en las elecciones. Lo anterior evidencia la necesidad de emplear estrategias de marketing viral en redes sociales para incrementar la participación de la población juvenil en las elecciones en el municipio Maracaibo.

Palabras clave: Marketing viral; jóvenes votantes; elecciones municipales; abstención.

\section{Viral marketing and Youth voter turnout}

\begin{abstract}
The aim of the research was to analyze the turnout causes in young voters and to determine the viral marketing impact as a voting motivator. The viral marketing (Sanagustin, 2010; Calderón, 2011) and the voter turnout (Ugarte et al, 2013; Trilla et al, 2010) were theoretically addressed. The descriptive-type research took on a population of 926.484 citizens registered in the National Electoral Council and a 156 units sample among the ages of 18 to 30 years old enabled to vote in the Municipal elections for mayor of Maracaibo (Venezuela) in the year 2013. Obtained results show
\end{abstract}

Recibido: 5.11.13. Aceptado: 05.03.15

* Licenciado en Comunicación Social (URBE), Magister en Gerencia de Mercadeo (URBE). Director de medios de Ideáticos Publicidad. E-mail: Lenin.rojas23@gmail.com.

** Licenciado en Comunicación Social (LUZ). Master en Administración (IESA).. Profesor AsociadoInvitado de la División de Estudios para Graduados. FCES. Universidad del Zulia, Venezuela. E-Mail: saavedra.mktg@gmail.com 
that psychological and political causes are the origins of youth voter turnout; the National Electoral Council does not fulfill the viral marketing phases, the voters follow up in social networks and the knowledge of the communication actions from the electoral entity influence by encouraging the electorate to participate in the election. The preceding evidences the need to employ viral marketing strategies in the social networks in order to increase the participation of young population in the Maracaibo municipal elections.

Key Words: Viral marketing; young voters; municipal elections; turnout.

\section{Introducción}

La abstención consiste en la no participación en el acto de votar de quienes tienen el derecho a hacerlo (Hernández, 2012). Es un no hacer o no obrar, el cual normalmente no produce efecto jurídico alguno, aunque en ocasiones puede ser considerada como la exteriorización de una determinada voluntad (Alcubilla, 2000).

Para Foix (2007), hay dos interpretaciones sobre la abstención en las elecciones en países democráticos. La primera es que la política tiene su propia dinámica, las cosas van relativamente bien, no hay miedos $y$, como consecuencia, no hay por qué ir a votar. La otra interpretación es menos optimista. Cuando los ciudadanos no acuden a votar es porque no esperan mucho de la política, no creen en los políticos y entonces acudir a las urnas no cambia nada. Esta segunda visión, enmarca a la abstención en el fenómeno más amplio de apatía participativa (Velazco, 2005).

Este escenario de poca participación es un hecho observado a nivel mundial: En Estados Unidos la participación en las elecciones presidenciales roza un $50 \%$ y en Europa las elecciones al Parlamento Europeo (PE) del 2009 la abstención fue de un 57\% (Ugarte et al, 2013). Sin embargo, esta realidad preocupante es mayor al analizar las bajísimas tasas de participación en los sectores juveniles de la población, pues parece responder a un manifestación general de desencanto respecto a la democracia y sus instituciones (Saha et al, 2007). A raíz de esto, en los últimos 30 años se ha desarrollado una creciente investigación sobre este fenómeno (Duke, 2008; Print y Milner, 2009; Ugarte et al, 2013).

Venezuela no escapa de esta realidad. Alcubilla (2000) analizó la abstención en tres periodos de la era democrática: a) en las elecciones presidenciales 1958, 1963, 1968 y 1973 la abstención se situó en un $5 \%$; b) en las tres siguientes elecciones (1978, 1983 y 1988) se comienza a producir un cambio en el comportamiento electoral, triplicándose la abstención para llegar a un $15 \%$; y c) a partir de 1992, en los procesos electorales presidenciales (1993, 1998, 2000 y 2006) la abstención electoral alcanza cifras entre un $43,7 \%$ en el 2000 a un $25,3 \%$ en el 2006.

Blander (2006:91) se cuestiona “¿Es la abstención en Venezuela una reacción de protesta ciudadana por la restricción de las libertades civiles y electorales? ¿Un síntoma de cansancio electoral? ¿Un síntoma de desafección por la democracia?”.

Según el Consejo Nacional Electoral (2008), la abstención para 
las elecciones regionales del año 2008 estuvo alrededor de un $40 \%$ a nivel nacional. Sin embargo, para las elecciones de los alcaldes del municipio Maracaibo (estado Zulia-Venezuela) la abstención se elevó de un $32,32 \%$ en el año 2008 hasta un $44,65 \%$ en el año 2010. En estas últimas, la abstención de la población de menos de 30 años llegó a un 58\%. Según Hernández (2012), la abstención en el estrato más joven es una de las más serias dificultades que debe evitar el sistema político venezolano si quiere continuar teniendo viabilidad democrática.

El fenómeno de abstencionismo electoral en la población joven sigue siendo un tema de profundo análisis para entender sus causas y motivaciones. Sin embargo, según Ugarte et al (2013) los jóvenes votantes siguen interesados en la política, pero no en su accionar a través de los canales y medios de la actividad política tradicional, sino a través de Internet y las redes sociales digitales de la Sociedad Red.

Esta Sociedad Red, enmarcada en un mundo digital, lo está cambiando todo. Según Muñoz (2007:4) "el universo digital se extiende en la sociedad y genera nuevos estilos de vida y nuevos hábitos de consumo". Nuevos estilos de vida en donde lo real y lo virtual, lo analógico y lo digital conviven y se mezclan generando una nueva realidad.

A este entorno no se escapa la actividad de la comercialización de bienes y servicios. El mercadeo ha incorporado a su gestión diversas metodologías, herramientas y conceptos de una comunicación en línea, surgiendo así el marketing digital (Muñoz; 2007).

En este sentido, las redes sociales juegan un papel importante para el marketing digital ya que constituye uno de los fenómenos de mayor crecimiento en Internet, debido a la capacidad de comunicación entre los usuarios (Singh y Sonnenburg, 2012). Por ello, se trata de un medio ambiente comunicacional idóneo para despertar vínculos emocionales entre los consumidores, los productos y aumentar el conocimiento de la marca (Priede y González, 2007).

Dentro del contexto del marketing digital y las redes sociales, surge el concepto de marketing viral, el cual es una técnica del marketing que utiliza la interconexión de los usuarios en las herramientas 2.0 para aumentar la difusión de campañas lanzadas por las marcas, y tiene como objetivo conseguir la difusión del mensaje en la red por la iniciativa de los internautas (Berger y Milkman, 2012).

El marketing viral, es como, su nombre lo indica, viral. Se trata que cierto tipo de mensajes se divulguen a través de un flujo de información incontrolado, como si de un virus informático se tratara; es decir, el marketing de boca a boca llevado al Internet. Cuando la fuente del mensaje merece confianza, el mensaje despierta la curiosidad de los receptores y aumenta su capacidad de propagación (Singh y Sonnenburg, 2012).

Al unir la afirmación en la cual los jóvenes votantes siguen interesados en la política, pero a través de la Sociedad Red (Ugarte et al, 2013), con el desarrollo del marketing digital y del marketing viral; se hace necesario el abordaje de esta realidad mediática y digital por todos los interesados en la actividad política (partidos, candidatos, organizaciones no-gubernamentales, institutos electorales, entre otros).

Esta nueva dimensión de análisis del quehacer político está generando nuevos términos como "democracia digital", o "e-democracia" (Magalhães y Villareal, 2012), "política 2.0" 
(Calderón, 2011), "democracia 2.0", "compromiso 2.0" (Sixto y Túñez, 2011), "ciberdemocracia" (Dader y Campos, 2006) o "actitud 2.0" (González y Petersen, 2010).

Hasta ahora la realidad electoral venezolana ha observado a partidos, políticos y candidatos involucrarse de manera activa en las redes sociales. Sin embargo, dichas acciones siempre han ido referidas a generar adeptos, simpatizantes y seguidores de una corriente política en particular, y no necesariamente a incentivar el voto masivo como ejercicio de acción democrática.

De este contexto, y entendiendo el "voto" como el resultado tangible de una dinámica participativa del proceso electoral democrático, nace el objetivo central de esta investigación: analizar las causas de la abstención de los jóvenes votantes y determinar el impacto del marketing viral como motivador del voto. El abordaje metodológico se realizó a través de una investigación descriptiva con un muestreo no probabilístico propositivo, recomendado por Kerlinger y Lee (2002) para estudios de mercado y encuestas políticas. La población estuvo constituida por 926.484 ciudadanos inscritos en el Consejo Nacional Electoral para participar en las elecciones municipales para alcalde de la ciudad de Maracaibo para el año 2013, obteniendo como muestra a 156 unidades informantes con edades comprendidas entre de 18 y 30 años y habilitados para votar en dicho proceso electoral.

\section{Abstención Juvenil}

En la búsqueda de entender el fenómeno de la abstención, y más concretamente la juvenil, se han realizado diversos estudios para comprender sus mecanismos de acción. Boneo y Torres (2000), indican que sólo votan quienes están en la flor de la edad; al hablar de esto se refiere directamente con la juventud.

Esta situación se contradice con Freire (2003); la edad constituye un factor que afecta la participación del ciudadano en muchos países, siendo los sujetos de mayor edad generalmente lo más participativos en estos procesos. Sin embargo, para Pérez (2006) la edad cronológica no es relevante, sino la experiencia y la adquisición de responsabilidades de orden político relacionadas con la edad.

Adicionalmente

se

han estudiado diversas causas capaces de generar abstención como variables sociodemográficas (Freire, 2003), educativas (Mark et al, 2006), económicas (Pérez, 2006), religiosas (Vilajosana, 1999), ambientales y de acceso o ubicación a los centros de voto (Soldevilla, 2003). Motivado a estos planteamientos, diversas entidades gubernamentales y privadas, como el Instituto Federal Electoral (México), International Institute for Democracy and Electoral Assistance (IDEA), The Electoral Commission (Reino Unido), Australian Electoral Commission (AEC), Elections Canada International Foundation for Election Systems (IFES), entre otros, han dedicado un considerable esfuerzo en estos últimos años en promover el voto juvenil aunque sin el resultado deseado aún (Ugarte et al, 2013).

$$
\text { Según Vilajosana }
$$

existen causas de la abstención juvenil merecedoras de consideración como son las socio-demográficos, 
psicológicas y políticas. Por otro lado, se hace importante destacar las causas señaladas por Boneo y Torres (2000) quienes señalan que los factores de la abstención electoral se deben precisamente a los vínculos individuales e institucionales de participación.

Desde las clasificaciones de las causas señaladas por ambos autores, se trabajará para efecto del estudio la clasificación de Vilajosana (1999), sustentada por los aportes de Boneo y Torres (2000). Adicionalmente se incorporan otras teorías que buscan analizar la abstención electoral juvenil desde la apatía política (Alcubilla, 2000) como reflejo claro de actitudes de desconfianza en las instituciones, desinterés por la política y desacuerdo con la oferta partidista disponible (Freire, 2003). Sin embargo, existe cada vez más una tendencia a explicar el fenómeno, no como un desinterés por la política, sino como un desplazamiento cultural producido en la experiencia política de los jóvenes (Trilla et al, 2010).

Según Ugarte et al, (2013) los jóvenes no están necesariamente menos interesados en la política que las generaciones anteriores; por lo contrario, la actividad política tradicional ya no parece apropiada para satisfacer las preocupaciones asociadas con la cultura juvenil contemporánea en la sociedad de la información.

Diversos autores apuntan un paralelismo donde al mismo tiempo que se desciende en las formas tradicionales de participación política (el voto y la afiliación a los partidos políticos, entre ellas), se incrementan otras formas habitualmente llamadas alternativas; esto es, mecanismos y modos de expresión democrática que privilegian las preocupaciones políticas cotidianas y la construcción de la identidad dentro del universo digital (Norris, 2002).

\section{Política en el mundo digital}

El universo digital, o en palabras de Castells (2006) la "Sociedad Red", nace centrada en las tecnologías de la información, las cuales están transformando aceleradamente las bases de las relaciones y las formas de comunicarnos a nivel humano, organizacional y político (Singh y Sonnenburg, 2012).

Para Muñoz (2007) el universo digital se extiende en la sociedad y genera nuevos estilos de vida, nuevas relaciones y nuevos hábitos de consumo; donde lo real y lo virtual, lo analógico y lo digital, conviven y se mezclan generando una nueva realidad. El imparable avance de Internet y de las redes sociales ha revolucionado los sistemas de comunicación, generando así un intercambio continuo y masivo de información.

Internet y la web 2.0 han supuesto un cambio estructural en el proceso comunicativo. Los roles de emisor y receptor se han modificado. La interacción entre ambos no es lineal sino multidireccional. Es decir, las figuras del emisor y del receptor quedan difuminadas hasta llegar a confundirse. De esta manera cualquiera de los dos puede adoptar el rol del otro, dando lugar a una comunicación construida entre todos (Fernández y Paniagua, 2012).

Así, como señala Blanco (2010:17) "El ciudadano ha pasado de convertirse en receptor pasivo de la información a creador y generador de contenidos. 
La web 2.0 le concede el poder de manifestarse y llegar a una audiencia potencial muy numerosa". Por ello, Internet se ha convertido rápidamente en una nueva fuente de información y de expresión, proporcionando una forma muy económica de manifestarse a los activistas políticos de todo el mundo, pues está cambiando las reglas del juego político (Martínez, 2012).

Tanto es el cambio de estas reglas que ya se empiezan a emplear nuevos términos como "democracia digital", o "e-democracia" (Magalhães y Villareal, 2012), "política 2.0" (Calderón, 2011), "democracia 2.0", "compromiso 2.0" (Sixto y Túñez, 2011), "ciberdemocracia" (Dader y Campos, 2006) o "actitud 2.0" (González y Petersen, 2010). Estos términos reflejan la transformación de los instrumentos de la democracia tradicional para hacer más eficaz la participación ciudadana en la toma de decisiones políticas y un mayor control de la cosa pública (Magalhães y Villareal, 2012).

En las redes sociales, y muy especialmente en Twitter, la e-democracia ha conseguido su mejor espacio para manifestarse. Calderón (2011) define este proceso como la aplicación de valores profundamente democráticos a la relación entre los políticos y los ciudadanos aprovechando las capacidades que la red y fundamentalmente las redes sociales, pone a la disposición de los individuos.

Actualmente en las redes se encuentran diversos activistas en línea (políticos, partidos, organizaciones no gubernamentales, individuos, grupos, entre otros) que hacen del Internet y las redes sociales su medio de lucha, con el cual buscan dar a conocer y visibilizar sus demandas, preferencias y descontento (Magalhães y Villareal, 2012). Estos crean espacios de participación en redes generalistas, donde si bien confluyen temáticas de diversa índole, suelen aprovechar sus múltiples cualidades y aplicaciones para gestionar contenidos políticos.

De esta forma, el espacio público se redefine y se virtualiza, estableciéndose fuera de los espacios políticos tradicionales, alejándose de las instalaciones de los partidos políticos y las entidades gubernamentales, los debates dejan de transmitirse por los medios de comunicación tradicionales para posicionarse en un entorno digital, al cual se puede acceder a cualquier hora y desde cualquier lugar (Henríquez, 2011).

Es precisamente la facilidad para opinar e interactuar con los pares uno de los elementos que más ha propiciado la incorporación del ciudadano común a la discusión sobre los temas públicos, especialmente al segmento juvenil como usuario natural de estas plataformas (Magalhães y Villareal, 2012).

La política se ha viralizado, usando como referencia el concepto de comunicación viral del mundo de marketing (Henríquez, 2011). Así, las estrategias de acción de "boca en boca" virtual se transforman en la principal herramienta de los ciber activistas - ciber políticos para difundir sus consignas o denuncias en las redes sociales. De esta forma, post, twits, "me gusta", audios, imágenes o videos, son ejemplo de esta técnica.

El mejor ejemplo de ello fue la campaña presidencial de Barack Obama en el año 2008. Basada en el marketing en línea y viral, fue "la primera en la historia en separar el 
departamento de redes sociales, que tradicionalmente estaba ubicado dentro del departamento de comunicación, para convertirlo en un departamento nuevo, reportando al director de campaña y con el mismo rango que el departamento de comunicación" (Martínez, 2012:19).

\section{Comunicación y marketing viral}

En los últimos años el marketing se ha visto influenciado por el mundo de la tecnología, cambiando radicalmente la interacción de las marcas y los consumidores a través de Internet. Sivera (2008) señala que las primeras campañas de publicidad para Internet se realizaban por separado, hasta Moliné (2000), quien demostró la efectividad de ubicar la publicidad con contenidos relacionados a lo que se está anunciando. Este marketing integrado tuvo un paso adicional cuando se incorporó a esos contenidos plataformas para crear conversaciones entre el público objetivo, y de esa forma añadir valor a la marca u organización.

Este valor radica en contenidos creados por la marca de tal forma que se vuelven interesantes para el público objetivo, impulsando a los propios receptores del mensaje a transformarse en emisores del mismo (Pérez; 2002). Al ser tan llamativos y contagiosos estos contenidos, las mismas audiencias quieren comunicarlos a sus amigos expandiéndolo a través de la red como si de un virus se tratase (Kottler, 2010).

Del Santo y Álvarez (2012) se refieren al marketing viral como "marketing de atracción 2.0", y lo diferencian del marketing de atracción original (o 1.0), en que el proceso de contacto cliente-marca no se inicia con la organización emitiendo mensajes publicitarios, sino todo lo contario. La filosofía del marketing de atracción 2.0 es radicalmente diferente al marketing tradicional donde se buscaba al consumidor (o votante) potencial a través de colocar avisos publicitarios en medios masivos.

El marketing de atracción 2.0 emplea un contenido de calidad y de interés para atraer a los clientes y lograr su arribo a través de las redes sociales, página web o blog por él mismo. En el marketing viral el potencial está en que el cliente no "se compra", por el contrario, "se gana" y "se atrae".

El marketing viral según Fernández (2004), implica la participación del usuario o cliente que, de modo voluntario, y movido por un interés compartido con su empresa reenvía, sus mensajes a sus amigos, recomendándoles la página web, el servicio o el producto. En este sentido, el marketing viral se fundamenta en estimular a los individuos, a los mismos clientes o usuarios de un servicio, a transmitir un mensaje promocional a otras personas de su entorno.

La principal ventaja de la comunicación viral es su capacidad de potenciar la credibilidad del mensaje, pues normalmente se recibe de un conocido. Cuando la fuente merece confianza, el mensaje despierta la curiosidad de los receptores (Singh y Sonnenburg, 2012). Por ello, se trata de un método especialmente bueno para despertar vínculos emocionales entre los consumidores, los productos y aumentar el conocimiento de la marca (Priede y González, 2007).

Sanagustin (2010) caracteriza el marketing viral con los siguientes 
aspectos: a) gratuidad: aunque se distribuyan gratuitamente, los contenidos han de tener suficiente valor añadido como para justificar hablar sobre ellos; b) exclusividad: los contenidos escasos o de accesos por invitación pueden convertirlos en deseados y altamente deseados por la comunidad, c) participación: los consumidores forman parte de los contenidos porque permiten la personalización, hablar de ellos es una manera de autopromocionarse; d) negatividad: la crítica o queja de alguien puede conseguir la solidaridad de otros usuarios; y e) sorpresa: captar la atención de los consumidores se consigue a través de contenidos insólitos ofrecidos sin mostrarse directamente como publicidad.

De acuerdo con Priede y González (2007) y Fernández (2004), el marketing viral tiene como objetivo conseguir que todos los clientes satisfechos actúen como prescriptores de los productos o servicios adquiridos. Esto se puede conseguir automáticamente de forma espontánea, o bien ser el resultado de programas específicos de incentivos. Es decir, el objetivo del marketing viral va en función de conseguir un nivel de satisfacción tan alto en los usuarios receptores de la acción de marketing que se sientan motivados a reenviar el contenido a otros usuarios potenciales

\section{Causas psicológicas y políticas de la abstención en votantes}

El estudio se realizó con la población juvenil votante del municipio Maracaibo del estado Zulia. Se consideraron como unidades de informantes a los hombres y mujeres entre de 18 y 30 años inscritos en el Consejo Nacional Electoral, habilitados para votar en las elecciones municipales para alcalde de la ciudad de Maracaibo para el año 2013.

Según datos del Consejo Nacional Electoral (2008), los votantes inscritos para el municipio Maracaibo eran 926.484 personas, definiéndose como una población finita. Debido a la imposibilidad de contar con el listado exacto de la distribución estratificada por edades del padrón electoral, se empleó un muestreo no probabilístico propositivo. Kerlinger y Lee (2002:160) recomiendan este muestreo para estudios de mercado y encuestas políticas ya que se "caracteriza por el uso de juicios e intenciones deliberadas para obtener muestras representativas al incluir grupos que se presume son típicos de la muestra".

Basado en lo anterior, y con el objetivo de lograr la mayor representatividad de la muestra, se abordaron a las unidades informantes entre las personas asistentes el lunes 30 de agosto de 2013 al simulacro convocado por el CNE para auditar el proceso electoral. Para participar en dicha simulación, el requisito indispensable era estar inscritos previamente en el padrón de votación.

El abordaje se realizó a la salida del proceso de simulacro electoral, donde se contactaba a los participantes y se les pedía participar en el estudio. Dos preguntas de control depuraban a los seleccionados: rango de edad e intención de asistir al acto de votación real. La muestra final quedó conformada por un total de 156 unidades, con las siguientes características demográficas presentadas en la Tabla 1. 


\section{Tabla 1}

Características demográficas de la muestra

\begin{tabular}{|c|c|c|c|c|c|c|c|c|}
\hline Edad & FA & $\%$ & Educación & FA & $\%$ & Educación & FA & $\%$ \\
\hline $18-20$ & 77 & $49 \%$ & Primaria & 12 & $8 \%$ & Zona Norte & 39 & $25 \%$ \\
\hline $21-24$ & 41 & $26 \%$ & Secundaria & 47 & $30 \%$ & Zona Sur & 58 & $37 \%$ \\
\hline $25-28$ & 22 & $14 \%$ & $\begin{array}{l}\text { Técnico superior } \\
\text { universitario }\end{array}$ & 29 & $19 \%$ & Zona Oeste & 42 & $27 \%$ \\
\hline $29-30$ & 16 & $10 \%$ & Universitaria & 68 & $44 \%$ & Zona Este & 17 & $11 \%$ \\
\hline Totales & 156 & $100 \%$ & Totales & 156 & $100 \%$ & Totales & 156 & $100 \%$ \\
\hline
\end{tabular}

Fuente: Elaboración propia (2015), a partir de los resultados de la investigación

A las 156 personas escogidas se les aplicó el instrumento de recolección de datos autoadministrado, estructurado en dos partes. La primera, relacionada con el marketing viral, para la cual se construyó una escala tipo Likert, donde cada entrevistado eligió entre cinco alternativas - categorías presentadas (desde totalmente de acuerdo, hasta totalmente en desacuerdo). La dimensión analizada fue "fases del marketing viral" y sus indicadores correspondieron a las fases de creación, optimización, promoción y conversión (Kottler, 2010; Del Santo y Álvarez, 2012).

Por su parte, la segunda sección del instrumento estaba relacionada con la variable de abstención electoral, y el cuestionario estuvo compuesto por 17 preguntas cerradas y abiertas. Las dimensiones analizadas fueron las causas psicológicas y las causas políticas de la abstención (Vilajosana, 1999; Boneo y Torres, 2000). Los indicadores de la variable causas psicológicas fueron: apatía-indiferencia (Alcubilla, 2000), desideologización o desinterés político (Freire, 2003), inutilidad del acto participativo y visión de las elecciones municipales (Vilajosana, 1999; Boneo y Torres, 2000). Por su parte, las dimensiones para las causas políticas de la abstención fueron: desconfianza en el árbitro electoral (Alcubilla, 2000), dominio de partidos políticos y su desvinculación de asuntos concretos de la vida comunitaria, ausencia de renovación de la clase política (Freire, 2003) y desencanto con el método tradicional de participación (Vilajosana, 1999; Boneo y Torres, 2000).

El instrumento fue sometido a una prueba para determinar su confiabilidad. Se aplicó la prueba de confiabilidad de alfa de Cronbach a las 156 unidades informantes de la muestra en estudio, obteniendo como resultado un alfa de 0,8725 ; lo cual indica un alto nivel de confiable del instrumento.

Se realizó la validez de contenido del instrumento, la cual es definida por Hernández et al (2006:244), como "la evaluación o revisión de las preguntas por parte de un grupo de jueces expertos en el área para garantizar la validez del contenido, es decir, si el instrumento mide lo que quiere medir".

La validez en el presente estudio se estableció a través del juicio de cinco (5) expertos en el área objeto de estudio, especialistas en gerencia, marketing, abstención electoral y un metodólogo en la modalidad de la investigación descriptiva, 
quienes evaluaron la pertinencia, redacción, extensión y secuencia de los ítems del cuestionario.

Luego del análisis metodológico se precisan los resultados relacionados con las causas psicológicas y políticas para la abstención en los votantes jóvenes en las elecciones municipales en la ciudad de Maracaibo. Posteriormente, se analiza el marketing viral y los usos generales de las redes entre los votantes consultados y su disposición de compartir información electoral a través de las redes sociales.

\subsection{Factores de abstención electoral}

Una vez obtenida toda la información relacionada con los factores de abstención electoral de las 156 personas consideradas en la muestra, se sumaron los puntajes en cada indicador, y así se obtuvieron las medias correspondientes para cada una de las 2 dimensiones estudiadas (causas políticas y psicológicas). Se empleó el análisis factorial para confirmar el aporte de cada indicador individual a cada dimensión. Se aplicó el análisis factorial para 3, 4, 5 y 6 factores (carga factorial de 0,5$)$ y se obtuvieron como óptimo agrupaciones en seis factores. De este resultado se depuraron los 22 indicadores para un óptimo de 14 factores.

Posteriormente se evaluaron los parámetros obtenidos en el modelo a través de un análisis correlacional para validar la influencia de cada uno de los indicadores obtenidos en el análisis factorial. Los resultados por cada indicador, con un nivel de significación de $5 \%(p<0,05)$ y su respectivo error estándar. La Tabla 2 muestra el resultado del análisis factorial.

\section{Tabla 2}

\section{Análisis factorial causas de la abstención electoral en jóvenes votantes}

\begin{tabular}{|c|c|c|c|c|c|c|c|}
\hline Grupos & Indicadores & 1 & 2 & 3 & 4 & 5 & 6 \\
\hline \multirow[t]{3}{*}{ Grupo 1} & Confianza CNE & 0,946 & & & & & \\
\hline & Resultado CNE & 0,961 & & & & & \\
\hline & Partidos conocen realidad & 0,953 & & & & & \\
\hline \multirow[t]{3}{*}{ Grupo 2} & Edad & & 0,912 & & & & \\
\hline & Ingreso económico & & 0,923 & & & & \\
\hline & Nivel educativo & & 0,858 & & & & \\
\hline \multirow[t]{2}{*}{ Grupo 3} & $\begin{array}{l}\text { Convencimiento de inutilidad del acto } \\
\text { participativo }\end{array}$ & & & 0,934 & & & \\
\hline & Voto contribuye municipio & & & 0,936 & & & \\
\hline \multirow[t]{2}{*}{ Grupo 4} & Ausencia renovación & & & & 0,916 & & \\
\hline & Nuevo liderazgo & & & & 0,923 & & \\
\hline \multirow[t]{2}{*}{ Grupo 5} & Inscripción partido políticos & & & & & 0,892 & \\
\hline & Confianza partido políticos & & & & & 0,871 & \\
\hline \multirow[t]{2}{*}{ Grupo 6} & Candidatos & & & & & & 0,760 \\
\hline & Confianza método elección & & & & & & 0,827 \\
\hline
\end{tabular}

Fuente: Elaboración propia (2015), a partir de los datos obtenidos en la investigación 
Para verificar la fiabilidad del constructo se empleó el indicador alfa de Cronbach y se fueron descartando los grupos de indicadores con menor carga estadística explicativa. La optimización del modelo con un alfa de
Cronbach de 0,855 quedó constituida por tres grupos de indicadores, que son los estadísticamente explicativos de la abstención electoral en la muestra seleccionada. La Tabla 3 muestra los resultados de la fiabilidad del constructo.

\section{Tabla 3}

\section{Fiabilidad del constructo de medición causas de la abstención electoral en jóvenes votantes}

\begin{tabular}{ccccc}
\hline & $\begin{array}{c}\text { Media } \\
\text { de la Escala } \\
\text { si el ítem es eliminado }\end{array}$ & $\begin{array}{c}\text { Varianza } \\
\text { de la Escala } \\
\text { si el ítem es } \\
\text { eliminado }\end{array}$ & $\begin{array}{c}\text { Correlación } \\
\text { Ítem-Total } \\
\text { corregida }\end{array}$ & $\begin{array}{c}\text { Alfa } \\
\text { de Cronbach } \\
\text { si el ítem es } \\
\text { eliminado }\end{array}$ \\
\hline Grupo 3 & 4,000 & 1,142 & 0,449 & 0,762 \\
Grupo 4 & 3,808 & 0,872 & 0,761 & 0,587 \\
Grupo 5 & 3,897 & 0,815 & 0,862 & 0,522 \\
\hline
\end{tabular}

Fuente: Elaboración propia (2015), a partir de los datos obtenidos en la investigación

Así pues, los indicadores con más carga estadística para explicar la abstención laboral son: a) Grupo 3: convencimiento de inutilidad del acto participativo, y percepción de que el voto contribuye a mejorar el municipio, b) Grupo 4: ausencia de renovación del liderazgo político y la necesidad de un nuevo liderazgo político, y c) Grupo 5: inscripción (vinculación) a partido políticos y la confianza en dichos partido políticos.

\subsection{Causas de abstención electoral}

Los indicadores del Grupo 3 exploran causas psicológicas de la abstención electoral. Al analizar en detalle los resultados de cada indicador, se observa como el referido al convencimiento de inutilidad del acto participativo obtuvo un resultado de $82,1 \%$ de quienes consideran que el voto de cada persona cuenta. Adicionalmente con relación al indicador sobre si el voto contribuye con el desarrollo del municipio, un $73,1 \%$ afirmó que votando está ayudando a desarrollar su localidad.

Estos resultados reflejan una realidad diferente al postulado de Vilajosana (1999) en relación a la llamada "paradoja del voto": la probabilidad de que un voto por separado incida en el resultado final es ínfima, cuando es una elección entre millones de personas. Sin embargo, al obtener un $82,1 \%$ de aceptación a la idea de que cada voto cuenta, los encuestados para la elección de alcalde del municipio Maracaibo expresan una valoración significativa del voto individual. 
Por su parte, los indicadores contenidos en el Grupo 4 exploran causas políticas de abstención electoral. El primer indicador considerado fue la percepción sobre la ausencia de renovación del liderazgo político, donde un $98,1 \%$ de los encuestados a votar en las elecciones municipales de Maracaibo señalaron la necesidad de renovar el liderazgo político en el municipio, y por otro lado, de un nuevo liderazgo de los partidos políticos, según un $97,4 \%$ de los entrevistados.

Si un electorado se abstiene, probablemente sus intereses no sean representados en el proceso político y fundamentalmente por los candidatos a elegir (Vilajosan, 1999). Basado en este postulado teórico y comparándolo con la contundencia de las afirmaciones obtenidas en la investigación se puede precisar la necesidad de la renovación del liderazgo político como un requerimiento urgente por parte de los marabinos en relación a la representación que buscan a través de los candidatos.

Estos resultados permiten constatar lo planteado por Boneo y Torres (2000), quienes indican que las opciones electorales constituyen la principal motivación de los votantes para asistir y ejercer su derecho al voto. De igual forma, estos resultados coinciden con los postulados de Freire (2003) para quien la abstención se refleja claramente en actitudes de desinterés por la política y una falta de motivación con la falta de renovación en la oferta de candidatos presentada por los partidos políticos.

Los indicadores del Grupo 5 exploran el desinterés político, y al analizar la data específica se observa un $67,3 \%$ de los encuestados indicaron no estar inscritos en ningún partido político. Del restante $32,7 \%$ de personas encuestadas, quienes indicaron estar inscritas en un partido político, un $89 \%$ manifestó no hacer vida en dichos grupos, puesto que su inscripción obedece a distintos factores personales, o por alguna oportunidad laboral. Adicionalmente, un $56,4 \%$ de los entrevistados señalaron su desconfianza hacia los partidos políticos aspirantes a la alcaldía del municipio Maracaibo.

Estos resultados pareciesen demostrar como la confianza en los partidos políticos constituye una fuerte influencia en la motivación para asistir al acto electoral, tal y como lo expone Freire (2003). Adicionalmente, los datos obtenidos corroboran el postulado de Vilajosana (1999): la abstención en los procesos electorales es una consecuencia cuando las personas sienten que sus intereses no se vean representados en los partidos políticos.

Adicionalmente, estos resultados coinciden con Boneo y Torres (2000) quienes señalan las ofertas electorales como una esperanza en el elector, una solución a sus problemas sociales, pero el incumplimiento de promesas pasadas, impulsa a pensar al elector a la hora de ejercer su derecho al voto, volviéndose más racional; perdiéndose así la vinculación emocional establecida en la campaña.

\subsection{Factores de marketing viral}

Para analizar los factores significantes del marketing viral, se empleó un método estadístico similar al empleado para las causas de la abstención electoral. Primeramente se sumaron los puntajes en cada indicador, para generar las medias correspondientes por cada indicador de los cuatro componentes teóricos estudiados del marketing viral (creación, 
optimización, promoción y conversión). Se empleó el análisis factorial para confirmar el aporte de cada indicador individual a cada dimensión. Se aplicó el análisis factorial para 3,4 y 5 factores (carga factorial de 0,5) y se obtuvieron como óptimo agrupaciones en dos factores. De este resultado, de los 9 indicadores analizados se obtuvo un óptimo de 7 factores.

Posteriormente se evaluaron los parámetros obtenidos en el modelo a través de un análisis correlacional para validar la influencia de cada uno de los indicadores obtenidos en el análisis factorial. Los resultados de la medida de adecuación muestral KMO (Test de Kaiser-Meyer-Oklin) de 0,771 y la prueba de esfericidad de Barlett con significación de alfa de $p \geq 0,000$, permiten asumir la robustez del análisis. La Tabla 4 muestra las agrupaciones producto del resultado del análisis factorial.

\section{Tabla 4}

\section{Análisis factorial marketing viral}

\begin{tabular}{llcl}
\hline Grupos & \multicolumn{1}{c}{ Indicadores } & $\mathbf{1}$ & $\mathbf{2}$ \\
\hline Grupo 1 & Campaña a través de redes sociales & 0,91 & \\
& Seguimiento en redes sociales & 0,96 & 0,94 \\
& Necesidad de incentivar al elector & 0,97 & 0,92 \\
& Incentivo a través de redes sociales & & 0,78 \\
& Acción de los organismo & & 0,81 \\
\hline
\end{tabular}

Fuente: Elaboración propia (2015), a partir de los datos obtenidos en la investigación

Se empleó el indicador alfa de Cronbach para verificar la fiabilidad del constructo. Se analizaron los siete (7) indicadores y se descartó el indicador "promoción electoral en redes sociales" porque afectaba el desempeño del modelo al disminuir el alfa esperado, al tener menor carga estadística explicativa. El resultado final fue un alfa de Cronbach de 0,905 , que es estadísticamente explicativo de la variable marketing viral. La Tabla 5 muestra los resultados de la fiabilidad del constructo. 


\section{Tabla 5}

\section{Fiabilidad del constructo de medición causas de la abstención electoral en jóvenes votantes}

\begin{tabular}{lcccc}
\hline & $\begin{array}{c}\text { Media } \\
\text { de la Escala } \\
\text { si el ítem es } \\
\text { eliminado }\end{array}$ & $\begin{array}{c}\text { Varianza } \\
\text { de la Escala } \\
\text { si el ítem es } \\
\text { eliminado }\end{array}$ & $\begin{array}{c}\text { Correlación item- } \\
\text { Total corregida }\end{array}$ & $\begin{array}{c}\text { Alfa de } \\
\text { Cronbach } \\
\text { si el ítem es } \\
\text { eliminado }\end{array}$ \\
\hline $\begin{array}{l}\text { Uso de las } \\
\text { redes sociales }\end{array}$ & 22,12 & 45,290 & 0,286 & 0,901 \\
$\begin{array}{l}\text { Marketing viral para impulsar } \\
\text { voto }\end{array}$ & 22,25 & 47,402 & 0,276 & 0,896 \\
$\begin{array}{l}\text { Campañas en } \\
\text { redes sociales }\end{array}$ & 23,81 & 35,524 & 0,880 & 0,843 \\
$\begin{array}{l}\text { Seguimiento en } \\
\text { redes sociales }\end{array}$ & 23,83 & 35,804 & 0,877 & 0,844 \\
$\begin{array}{l}\text { Necesidad de Incentivar al } \\
\text { elector }\end{array}$ & 23,56 & 33,873 & 0,877 & 0,842 \\
$\begin{array}{l}\text { Incentivo en } \\
\text { redes sociales }\end{array}$ & 23,66 & 34,626 & 0,895 & 0,841 \\
$\begin{array}{l}\text { Acción de } \\
\text { organismo }\end{array}$ & 23,88 & 36,172 & 0,833 & 0,849 \\
\hline
\end{tabular}

Fuente: Elaboración propia (2015), a partir de los datos obtenidos en la investigación

\subsection{Marketing viral y usos de las redes entre los votantes}

El primer grupo analizado fue el constituido por los indicadores: uso activo de las redes sociales e impacto del marketing viral como una herramienta para impulsar el voto. Con respecto al uso activo de las redes sociales entre los votantes inscritos a las elecciones municipales de Maracaibo, un $63,5 \%$ de los encuestados respondió estar totalmente de acuerdo con relación al uso activo de las redes sociales, mientras un $19,9 \%$ indicó estar de acuerdo. Así, un $82,4 \%$ de la muestra actualmente hacen uso de las redes sociales.

Esta masificación en el uso de las redes sociales es el principal factor expuesto por Sanagustin (2010) para poder ejecutar algún tipo de plan de marketing viral pues es necesaria una masa crítica capaz de distribuir el contenido entre sus contactos y relacionados. Un $82,4 \%$ de personas se definen como activas en las redes sociales, y exponen claramente el uso extendido de estas herramientas de comunicación entre la muestra estudiada.

Al consultárseles su opinión sobre el impacto del marketing viral como una herramienta para impulsar el voto en la región, un $52,6 \%$ de la muestra encuestada respondió estar de acuerdo, y un $35,3 \%$ se encuentra totalmente de acuerdo. De manera que un $88,9 \%$ de las personas entrevistadas considera importante para la promoción electoral dicha estrategia.

Al entender los encuestados el marketing viral como una herramienta de 
promoción coincide con los postulados de Fernández (2004), quien expone la necesidad de la participación del usuario o cliente que, de modo voluntario, y movido por un interés compartido con el producto o servicio (en este caso, el proceso electoral) reenvía sus mensajes a sus amigos, recomendándoles la página web, el servicio o el producto.

De igual forma, un $88,9 \%$ de la muestra considera idóneo el marketing viral para la promoción electoral. Ello coincide con lo expuesto por Pérez (2002) y Kottler (2010) quienes consideran la predisposición favorable a los contenidos creados por la marca por parte de los consumidores, como un factor determinante en que los propios receptores del mensaje se transforman en emisores del mismo, al reproducir el mensaje entre sus amigos y contactos.

El segundo grupo de indicadores estudiados estuvo compuesto por: recordación de campañas en redes sociales, seguimiento a través de las redes sociales por parte de los electores del ente encargado (CNE), necesidad de incentivar al elector, incentivo al elector a través de las redes sociales y conocimiento de la acciones de comunicación del organismo.

Con relación a los dos primeros indicadores de este grupo, recordación de campañas en redes sociales y seguimiento a través de las redes sociales por parte de los electores de los entes encargados, un $67,9 \%$ de los encuestados manifestó no haber visto ningún esfuerzo electoral a través de sitios como Facebook, Twitter, Instagram o Youtube; mientras un $77 \%$ reportó no seguir a los organismos electorales en las redes sociales.

Esta falta de percepción del público votante juvenil sobre las acciones del ente comicial a las elecciones municipales en Maracaibo, va en contradicción a los postulados de Henríquez (2011) y Magalhães y Villareal (2012) quienes explican como el espacio público se ha redefinido y virtualizado, generando debates fuera de los espacios políticos tradicionales, para posicionarse en un entorno digital. Esto facilita la incorporación del ciudadano común a la discusión sobre los temas públicos, especialmente al segmento juvenil usuario de estas plataformas

Adicionalmente se puede observar una disonancia con lo expuesto por Del Santo y Álvarez (2007), pues la optimización es considerada como la fase del posicionamiento, en donde el público encuentra fácilmente la propuesta de valor. Sin embargo, los resultados demuestran un pleno desconocimiento sobre las comunicaciones emitidas en redes sociales por el ente comicial.

Estos hallazgos se contradicen con Priede y González (2007) y Fernández (2004): el objetivo del marketing viral va en función de obtener usuarios receptores de la acción de marketing tan satisfechos que reenvíen a otros usuarios potenciales. Este objetivo es imposible de alcanzar si el público objetivo encuentra poco atractivas las comunicaciones y los esfuerzos promocionales del ente electoral venezolano.

Los siguientes indicadores analizados fueron la necesidad de incentivar al elector y el incentivo al elector a través de las redes sociales. En los datos obtenidos un significativo $92,3 \%$ de los entrevistados considera necesario de incentivar al elector a participar en las elecciones municipales a través de cualquier medio, y un 93\% consideró que se debería hacer específicamente a través de las redes sociales.

Desde esta perspectiva, cabe referir a Del Santo y Álvarez (2012), 
cuando dentro de sus fases señalan que la promoción debe provocar una conversación dentro de la red, incentivando así las discusiones sobre un tema en específico, donde el ente comicial debería ser el encargado de llevar la interactividad entre los electores, convirtiéndose en motivo de propagación del mensaje. De esta manera se evidencia un claro deseo de los encuestados en ser tomados en cuenta para los comicios electorales.

Ahora bien, Priede y Gonzalez (2007) señalan que a través del mensaje el marketing viral puede llegar a despertar la curiosidad de los receptores, creando así un vínculo emocional entre el público y la marca. De esta misma manera el electorado espera ser motivado a través de las redes sociales y las distintas herramientas digitales para propagar el mensaje.

El último de los indicadores analizados fue el conocimiento por parte de los electores de la acciones de comunicación del organismo. En los datos obtenidos tan sólo un $23,1 \%$ de las personas afirmaron conocer si los organismos encargados difunden a través de las redes sociales las campañas electorales.

Estos datos reflejan una profunda desconexión con lo planteado por Henríquez (2011) quien considera que las estrategias de acción de "boca en boca" virtual se han transformado en la principal herramienta de los ciber activistas o ciber políticos para difundir sus consignas o denuncias en las redes sociales.

Dada esta nueva condición de comunicación, es el mismo CNE el ente idóneo para asumir el rol de propagador de información que motive al elector a asistir a los comicios electorales, y genere una transmisión de información
(Fernández, 2004), de manera voluntaria, a través vínculos emocionales entre los consumidores (electores) y los productos (el voto) para aumentar el conocimiento y atracción por ello (Priede y González, 2007).

\subsection{Influencia del marketing viral en la intención de voto de las elecciones municipales de Maracaibo}

Los resultados anteriormente expuestos, reflejan una realidad sobre el estado de la comunicación empleada por el CNE en las redes sociales para las elecciones municipales de la ciudad de Maracaibo. Una mayoría significativa de la muestra estudiada manifestó desconocer la información oficial generada por el ente comicial. De igual manera, expresaron no observar una comunicación atractiva que los induzca a votar.

Basado en lo anterior, y como parte final del presente trabajo se estableció estadísticamente la posible influencia del marketing viral en la intención de voto de las elecciones municipales de Maracaibo. Con los resultados obtenidos, se procedió a verificar el comportamiento de los estadísticos. Dado que la curtosis y la asimetría se ubican en el rango de +/- 2 y la muestra es mayor a 30 sujetos (156), es factible asumir que no existen elementos para desechar la normalidad de los datos, en consecuencia se aplicaron las pruebas paramétricas $\mathrm{t}$ de Student $\mathrm{y}$ análisis de la varianza (ANOVA), las cuales permitieron efectuar la comparación entre indicadores.

A fin de comparar la incidencia del marketing viral sobre la intención de voto de las elecciones municipales de Maracaibo, se aplicó la prueba t de 
Student para muestras relacionadas, evidenciándose que existen diferencias altamente significativas en la percepción de los encuestados con respecto a ambas ( $\mathrm{t} \geq 8.41$ y sig. $<0.01$ ).

Posteriormente, a fin de determinar si las diferencias entre los indicadores de marketing viral (uso activo de las redes sociales, impacto del marketing viral como una herramienta para impulsar el voto, recordación de campañas en redes sociales, seguimiento a través de las redes sociales por parte de los electores del ente encargado (CNE), necesidad de incentivar al elector, incentivo al elector a través de las redes sociales y conocimiento de la acciones de comunicación del organismo) presentaban relevancia estadística significativa en su aporte a la intención de voto de las elecciones municipales de
Maracaibo, se realizó un análisis de la varianza (ANOVA).

El análisis de varianza detectó que efectivamente existían fundamentos para afirmar la variabilidad en sólo dos de los factores analizados: seguimiento a través de las redes sociales por parte de los electores del ente encargado $(f=8,343$ con significancia $p=0,004)$ y conocimiento de la acciones de comunicación del organismo $(\mathrm{f}=9,522$ con significancia $p=0,002)$. La diferencia significativa detectada se ubicó a través de la prueba de múltiples rangos de Tukey, declarando que entre ambos indicadores no se podía declarar variación, por lo que ambos tienen similar preponderancia. La Tabla 6 presenta los resultados del análisis de la varianza (ANOVA).

\section{Tabla 6}

Análisis de varianza (ANOVA) marketing viral sobre la intención de voto de las elecciones municipales de Maracaibo

\begin{tabular}{|c|c|c|c|c|c|c|}
\hline \multicolumn{7}{|c|}{ ANOVA } \\
\hline Indicador & & $\begin{array}{l}\text { Suma de } \\
\text { Cuadrados }\end{array}$ & $\mathrm{df}$ & $\begin{array}{l}\text { Cuadrado } \\
\text { de Media }\end{array}$ & $\mathrm{F}$ & Sig. \\
\hline \multirow{3}{*}{$\begin{array}{l}\text { Uso de las } \\
\text { redes sociales }\end{array}$} & Entre Grupos & 0,262 & 1 & 0,262 & 0,217 & 0,642 \\
\hline & Dentro de Grupos & 186,404 & 154 & 1,210 & & \\
\hline & Total & 186,667 & 155 & & & \\
\hline \multirow{3}{*}{$\begin{array}{l}\text { Marketing viral } \\
\text { para impulsar } \\
\text { voto }\end{array}$} & Entre Grupos & 0,690 & 1 & 0,690 & 1,293 & 0,257 \\
\hline & Dentro de Grupos & 82,150 & 154 & 0,533 & & \\
\hline & Total & 82,840 & 155 & & & \\
\hline \multirow{3}{*}{$\begin{array}{l}\text { Campaña a } \\
\text { través de } \\
\text { redes sociales }\end{array}$} & Entre Grupos & 0,944 & 1 & 0,944 & 0,769 & 0,382 \\
\hline & Dentro de Grupos & 188,954 & 154 & 1,227 & & \\
\hline & Total & 189,897 & 155 & & & \\
\hline
\end{tabular}

Fuente: Elaboración propia (2015), a partir de los datos obtenidos en la investigación 


\section{Cont... Tabla 6}

\begin{tabular}{|c|c|c|c|c|c|c|}
\hline \multicolumn{7}{|c|}{ ANOVA } \\
\hline Indicador & & $\begin{array}{l}\text { Suma de } \\
\text { Cuadrados }\end{array}$ & $\mathrm{df}$ & $\begin{array}{l}\text { Cuadrado } \\
\text { de Media }\end{array}$ & $\mathrm{F}$ & Sig. \\
\hline \multirow{3}{*}{$\begin{array}{l}\text { Seguimiento en } \\
\text { redes sociales }\end{array}$} & Entre Grupos & 9,378 & 1 & 9,378 & 8,343 & 0,004 \\
\hline & Dentro de Grupos & 173,103 & 154 & 1,124 & & \\
\hline & Total & 182,481 & 155 & & & \\
\hline \multirow{3}{*}{$\begin{array}{l}\text { Necesidad de } \\
\text { incentivar al } \\
\text { elector }\end{array}$} & Entre Grupos & 0,147 & 1 & 0,147 & 0,368 & 0,545 \\
\hline & Dentro de Grupos & 61,769 & 154 & 0,401 & & \\
\hline & Total & 61,917 & 155 & & & \\
\hline \multirow{3}{*}{$\begin{array}{l}\text { Incentivo a } \\
\text { través de } \\
\text { redes sociales }\end{array}$} & Entre Grupos & 0,093 & 1 & 0,093 & 0,232 & 0,631 \\
\hline & Dentro de Grupos & 61,926 & 154 & 0,402 & & \\
\hline & Total & 62,019 & 155 & & & \\
\hline \multirow{3}{*}{$\begin{array}{l}\text { Acción de los } \\
\text { organismo }\end{array}$} & Entre Grupos & 8,410 & 1 & 8,410 & 9,522 & 0,002 \\
\hline & Dentro de Grupos & 245,814 & 154 & 1,096 & & \\
\hline & Total & 256,224 & 155 & & & \\
\hline
\end{tabular}

Fuente: Elaboración propia (2015), a partir de los datos obtenidos en la investigación

Esta verificación estadística de la influencia de los indicadores "seguimiento a través de las redes sociales por parte de los electores del ente encargado" y "conocimiento de la acciones de comunicación del organismo", coincide con lo expuesto por Ugarte et al (2013) quienes plantean que los jóvenes votantes siguen interesados en la política, pero no a su accionar a través de los canales y medios de la actividad política tradicional, sino a través de Internet y las redes sociales digitales.

\section{Conclusiones}

Las causas psicológicas de abstención en la población marabina hacia las elecciones municipales, las mismas se centran tanto en el convencimiento de inutilidad del acto participativo, en contraposición a la percepción de los electores quienes consideran que su voto es tomado en cuenta para contribuir al desarrollo de la ciudad.

Adicionalmente quedó evidenciado a través de las pruebas estadísticas que unas de las causales de abstención en el municipio Maracaibo es la falta de credibilidad en los partidos políticos, debido a la trayectoria de promesas no cumplidas por parte de los actores políticos de la ciudad. Este motivador va en paralelo con la no inscripción en los partidos políticos. Estos resultados permiten concluir que el rol de las organizaciones partidistas, que en generaciones anteriores fue determinante en el proceso democrático venezolano, ha perdido su poder para motorizar e incentivar a la población juvenil a ejercer su derecho al voto. 
Las causas políticas de abstención del electorado joven hacia las elecciones del municipio Maracaibo, se puede concluir que el mayor impacto radica en la percepción de ausencia de renovación del liderazgo político y la necesidad de un nuevo liderazgo político. Nuevamente queda en evidencia, que para la muestra del presente estudio el liderazgo y el rol de los partidos políticos tradicionales está perdiendo fuerza a la hora ser el catalizador de la intención al voto.

En cuanto a las fases de marketing viral se puede concluir que las mismas no son asumidas por el ente encargado, en este caso el CNE para las elecciones municipales de la ciudad de Maracaibo. Se manifiesta un alto grado de desconocimiento de la información oficial por parte de los electores, quienes manifiestan no conseguir u observar información atractiva o relevante que los impulse a votar. Es decir, no dan cumplimiento a las fases del marketing viral, tales como: creación, optimización, promoción y conversión del contenido.

Con respecto al impacto del marketing viral como motivador del voto de las elecciones municipales de Maracaibo, se concluye que los aspectos "seguimiento a través de las redes sociales por parte de los electores del ente encargado" y "conocimiento de la acciones de comunicación del organismo", tienen una clara influencia en la motivación al voto del electorado juvenil.

Por ello, la combinación entre el altísimo nivel de vinculación del electorado juvenil con las redes sociales y el alto grado de confianza manifestado por los encuestados en el árbitro electoral y el sistema de votación, constituye un punto a favor para incentivar al voto, a la vez de punto de partida para la creación de estrategias virales para incentivar al electorado a ejercer su derecho al voto.

\section{Basado en los hallazgos} anteriormente comentados, se recomienda al ente comicial cuatro grandes estrategias de marketing viral para disminuir la abstención del votante en el proceso eleccionario de alcaldes del municipio Maracaibo: a) crear redes sociales y contenido para los electores, b) posicionar las redes y el contenido del CNE en motores de búsqueda online, c) promocionar el evento electoral a través las redes sociales y la web del $\mathrm{CNE}$, mediante distintas estrategias creativas, y d) emplear la plataforma 2.0 del CNE para propiciar intercambio y acercamiento entre los electores y candidatos. Este tipo de estrategias generará un mayor tráfico en las redes y cimentará la actual confiabilidad en el CNE, y pudiese trasladar parte de la misma hacia los aspirantes a los Consejos Municipales y la Alcaldía de Maracaibo.

Finalmente, hoy en día, donde la sociedad de la comunicación, la información, y las tecnologías prevalecen en los diferentes espacios, se hace necesario considerar el uso de las diversas formas de publicidad para mercadear una información o producto a través de las redes sociales. De allí, la relevancia de la investigación sobre el marketing viral como estrategia para incentivar el intercambio de información a través de estas redes, siendo uno de estos intercambios comunicacionales, los procesos electorales.

Es cierto que esta investigación no es concluyente ni definitoria del comportamiento de los votantes de la ciudad de Maracaibo, ni de toda Venezuela, sin embargo puede ser el punto de partida para futuras investigaciones sobre la vinculación del fenómeno comunicacional viral y el fenómeno electoral. 


\section{Referencias Bibliográficas}

Alcubilla, Enrique (2000), El régimen electoral en España. Centro de Estudios Políticos y Constitucionales. Madrid. España

Berger, Jonah and Milkman, Katherine (2012), What Makes online Content Viral? Journal of Marketing Research. Vol. XLIX, pp 192-205.

Blanco, Sonia (2010), Del blog al microblog: el devenir del receptor en generador y emisor de contenidos en la Web 2.0. Universidad de Málaga. Málaga. España.

Blander, Natalia (2006), La abstención en Venezuela: ¿desafección o protesta democrática? Revista Politeia. Instituto de Estudios Políticos. Universidad Central de Venezuela. Vol. 29, N 37, pp 89-122.

Boneo, Horacio y Torres, Edelberto (2000), ¿Por qué no votan los guatemaltecos? Estudio de participación y abstención electoral. Tribunal Supremo Electoral. Guatemala

Calderón, Carlos (2011), Manual del e-líder. En G. Alarcón y J. Llinares (Coords.). Política 2.0: las campañas electorales en la red. Granada. España.

Castells, Manuel (2006), La Sociedad Red. Madrid. Alianza Editorial.

Consejo Nacional Electoral (2008), Divulgación Elecciones Regionales 2008. Página web del ente comicial. Disponible en: http://www.cne.gov. ve/web/registro_electoral_descarga/ abril2012/nacional.php Fecha de consulta: 10 de octubre de 2013.

Dader, José Luis y Campos, Eva (2006), Internet parlamentario en España (1999-2005): Los recursos para el contacto ciudadano y su uso, con una comparación europea. ZER. Revista de Estudios de Comunicación. Universidad del País Vasco. Vol. 11:20, pp. 105-132.
Del Santo, Oscar y Álvarez, Daniel (2012), Marketing de Atracción 2.0. "Cómo conseguir objetivos online con el mínimo presupuesto". España: New Ebook.

Duke, Chris (2008), University Engagement: Avoidable Confusion and Inescapable Contradiction. Higher Education Management and Policy. Vol. 20, № 2, pp 1-11.

Fernández, Eva (2004), Conocimientos y aplicaciones tecnológicas para la dirección comercial. España: ESIC.

Fernández, María y Paniagua, Francisco (2012), El Poder de las redes sociales en la política y en los movimientos sociales. I Congreso Internacional en Comunicación Política y Estrategias de Campaña. Mesa No 23: "Gestión política, campañas y nuevas tecnologías". Madrid. España.

Foix, LLuis (2007), Algunas causas de la Abstención electoral. Disponible en http://www.foixblog. com/2007/05/18algunas-causas-dela-abstencion-electoral. Fecha de consulta: 10 de octubre de 2013.

Freire, André (2003), Elecciones y comportamiento electoral en Portugal. En Portugal: Democracia y Sistema Político. España: Siglo Veintiuno. Argentina Editores.

González, Vanessa y Petersen, María (2010), El alcance de Twitter como herramienta política. Revista Orbis. Vol. 16, N 5 , pp 98-116.

Henríquez, Maryan (2011), Clic Activismo: redes virtuales, movimientos sociales y participación política. Revista Teórica de la Facultad de Ciencias Sociales. Universidad de Playa Ancha. Chile. Año 7, Vol. 13. Disponible en: http://web.upla.cl/ revistafaro/n13/art04.htm. Fecha de consulta: 03 de noviembre de 2013.

Hernández, Roberto; Fernández, Carlos y Baptista, Pilar (2006), Metodología de la Investigación. 4ta Edición. McGraw-Hill Interamericana. México. 
Hernández, Manuel (2012), La variable abstención. En Diario del pueblo Región Oriente, publicado en Opinión. 24 de septiembre de 2012.

Kerlinger, Fred y Lee, Howard (2002), Investigación del comportamiento. Métodos de Investigación en Ciencias Sociales. (4ta. Ed). México: Mc Graw Hill.

Kottler, Phillip. (2010), Dirección de Marketing. Edición Milenio. México. Editorial Pearson Educación de México S.A. de C.V.

Magalhães, Leonardo y Villareal, María (2012), La democracia digital en los discursos $y$ en las prácticas comunicativas: Análisis comparado de la comunicación 2.0 de Avaaz y Amnistía Internacional. I Congreso Internacional en Comunicación Política y Estrategias de Campaña. Mesa No 23: "Gestión política, campañas y nuevas tecnologías". Madrid. España.

Mark, Payne; Zovatto, Daniel y Mateo, Mercedes (2006), La Política Importa: Democracia y desarrollo en América Latina. Banco Interamericano de Desarrollo y el Instituto Internacional para la Democracia y la Asistencia Electoral. Washington, D.C.

Martínez, Martín (2012), Redes sociales y política 2.0: Presencia en Twitter de los candidatos a las elecciones andaluzas de 2012. Tesis de Grado. Máster Universitario en Comunicación Institucional y Política. Universidad de Sevilla

Moliné, Marçal (2000), La fuerza de la publicidad: saber hacer buena publicidad, saber administrar su fuerza. Universidad Antonio de Nebrija.

Muñoz, Pablo (2007). Estrategias de marketing digital para Pymes. España. ANETCOM.

Norris, Pippa (2002), Democratic Phoenix. Cambridge, UK. Cambridge University Press.
Pérez, Carmen (2006), Enfoques teóricometodológico en el estudio de la participación electoral. Revista Cuestiones Políticas. Vol. 22, $\mathrm{N}^{\circ} 37$, pp 75-93.

Pérez, Enrique (2002), Comunicación fuera de los medios: "Below the line". España: ESIC.

Priede, Tiziana, y González, César. (2007). Marketing Móvil: una nueva herramienta de comunicación. España. Oleiros, Netbiblo.

Print, Murray y Milner, Hemry (eds.) (2009), Civic Education and Youth Political Participation. Rotterdam: Sense Publishers.

Saha, Lawrence; Print, Murray y Edwards, Kathy (eds.) (2007), Youth and Political Participation. Rotterdam: Sense Publishers.

Sanagustin, Eva (2010), Marketing 2.0 en una semana. España: Grupo Planeta.

Singh, Sangeeta y Sonnenburg, Stephan (2012), Brand Performances in Social Media. Journal of Interactive Marketing. Vol. 26, pp 189-197.

Sivera, Silvia (2008). Marketing viral. España: UOC.

Sixto, José y Túñez, Miguel (2011), Redes sociales, política y Compromiso 2.0: La comunicación de los diputados españoles en Facebook. Revista Latina de Comunicación Social, $N^{\circ}$ 66. Disponible en: http://www.revistalatinacs.org /11/art/930 Santiago/RLCS art931. pdf Fecha de consulta: 14 junio 2012.

Soldevilla, Fernando (2003), Abstencionismo o ausentismo ¿Son iguales? XVII Conferencia Protocolo de Tikal, IIDH/ CAPEL.

Trilla, Jaume; Jover, Gonzalo; Martínez, Miguel y Romañá, Teresa (2010), La participación de los estudiantes en el gobierno y vida universitaria, en Jover, G.; Belando, M.; González, R. (eds). Formación y participación de los estudiantes en la Universidad. 
Madrid: Universidad Complutense de Madrid.

Ugarte, Carolina; Reparaz, Charo y Naval, Concepción (2013), Participación y abstención de los jóvenes en las elecciones al Parlamento Europeo de 2009. Una respuesta desde la Educación Cívico-Política. Educación XX1. Vol. 16, № 2, pp 209230. doi: 10.5944/educxx1.16.2.2640
Velazco, Meralia (2005), Legalidad y legitimidad de las comunidades organizadas en los consejos locales de planificación pública. Tesis de Doctorado en Ciencia Política, Universidad Simón Bolívar.

Vilajosana, Josep (1999), La justificación de la abstención. Revista de Estudios Políticos. N 104, pp 165-180. 